\title{
NUMERICAL ANALYSIS OF A PHOTOVOLTAIC MODULE INTEGRATED WITH VARIOUS WATER COOLING SYSTEMS
}

\begin{abstract}
Summary
As the main drawback of a photovoltaic module is its high operating temperature, various designs for cooling the module are presented in this study. Computational fluid dynamics (CFD) software is used for simulating the presented models. In these models, water channels are placed above or below the panel to cool the module and heat the water at the same time. In two designs, aluminium fins are attached to the bottom side of the panel inside the water channel. The water outlet temperature, pressure drop and heat flux from the panel are calculated at various Reynolds numbers. The results show that as the Reynolds number increases, the heat flux and the pressure drop increase while the coolant average outlet temperature decreases. The highest amount of heat flux is obtained from Model A, which indicates that this model has a better cooling capacity than other models investigated in the study.
\end{abstract}

Key words: $\quad$ Photovoltaic panel, numerical analysis, ANSYS, cooling channels

\section{Introduction}

Among different renewable energy technologies, photovoltaic (PV) systems are the most common ones used to generate electricity from sunlight. PVs do not produce pollutants during operation; they have low operating costs and need very low maintenance [1]. However they have some drawbacks, such as low efficiency level, dependence on inverters and storage batteries, and high investment and insurance costs. The performance of a PV system can be affected considerably by its operating surface temperature [2]. Due to an increase in the PV module surface temperature of $1{ }^{\circ} \mathrm{C}$, there is about a $0.5 \%$ reduction in the efficiency of the system [3]. The rise in the surface temperature of the cell prevents the total amount of the solar energy absorbed to be converted into electrical energy. As a result, the remaining solar energy will be converted into heat. In order to improve the overall performance of PV modules, various cooling techniques are introduced and examined by researchers. Peng et al. [4] investigated the practical effects of solar PV surface temperature on the output performance. Experimental studies were also carried out under different radiation conditions. A cooling system was proposed for a possible system setup of residential solar PV 
application. The findings showed that with the proposed cooling system, the efficiency of the PV could be increased by $47 \%$.

In order to control the temperature of the PV module during its operation, a passive temperature control technique with heat spreaders and cotton wicks was developed. The test results showed that the PV module temperature was reduced by $12 \%$ while the electrical performance was increased by $14 \%$ [5]. To investigate the effect of water spray cooling on the PV panel performance, an alternative cooling technique was developed [6]. In that technique, both sides of the panel were cooled simultaneously. With the proposed model, the panel temperature was decreased from an average $54^{\circ} \mathrm{C}$ to $24^{\circ} \mathrm{C}$. Also, a maximal total increase of $7.7 \%$ in the electric power output was observed.

A laboratory scale experimental setup was developed in [7] with intermittent and continuous water cooling systems. Irradiance was varied from $87.38 \mathrm{~W} / \mathrm{m}^{2}$ to $359.17 \mathrm{~W} / \mathrm{m}^{2}$. Three different flow rates of $3 \mathrm{lit} / \mathrm{min}, 5.3 \mathrm{lit} / \mathrm{min}$, and $6.2 \mathrm{lit} / \mathrm{min}$ were used in the tests. The test results showed an increase of about $18 \%$ in the total amount of energy produced for all three cases. In another study, [8], two models, a steady-state and a dynamic model, were developed in order to examine the panel operating temperature behaviour. In the proposed models, water was used as the cooling medium. To validate the mathematical model, empirical investigations were also carried out. Various parameters, such as the distance between nozzles, nozzle sizes, and the angles of spread of jets were changed in each test. By utilizing nine water nozzles with the angle of spread of $90^{\circ}$ and a total water flow rate of $0.09 \mathrm{lit} /\left(\mathrm{m}^{2} \mathrm{~s}\right)$, acceptable results were achieved. The authors of the study found that the gap between the cooled and non-cooled steady-state temperatures was within the 8 to $24^{\circ} \mathrm{C}$ range. Rajput and Yang [9] investigated the performance of a PV module with cylindrical pin fin heat sinks attached underneath and compared the results with a traditional single-channel $\mathrm{PV} / \mathrm{T}$ collector. The analysis showed $30 \%$ and $41.5 \%$ enhancements in the heat flux at the panel rear side using a heat sink and a PV/T collector, respectively.

It is known that as the flow velocity over the panel increases, the cooling performance increases as well but at the same time this enhances the power consumption [10]. Krauter [11] showed that the water flow enhances the panel electrical efficiency by $8-9 \%$ and at the same time reduces the reflection losses. Researchers applied various methods to improve the overall performance of the PV panel [12]. Some researchers used a converging channel heat exchanger [13], some employed intermittent water cooling with a sun tracking system [14], some installed a water sprinkle on the front surface of a PV module [15] or included a water film cooling system to the front surface of the panel [16]. In the study [17], three types of passive cooling, including water, air, and conductive passive cooling, were applied to a PV module; as a result, a 3\% increase in the efficiency was reported. In a cost-effective cooling method introduced by Sajjad et al. in [18], PV panels were installed on the cooled air ducts of the air conditioners used in buildings. A $6 \%$ increase in the performance ratio was observed with this method.

The aim of this study is to numerically investigate the effect of different configurations on the PV panel heat flux and coolant temperature. With the proposed design, the PV module can be cooled while the heated water could be used elsewhere. Six models were designed and simulated using computational fluid dynamics (CFD) software. In each simulation, changes in the heat flux and the coolant outlet temperature at different Reynolds number are observed. In two models, aluminium fins are placed in the bottom channel to examine their effect on the heat flux and the coolant temperature. 


\section{Methodology}

In order to reduce the PV module surface temperature, various cooling techniques are introduced and examined by researchers. Both air and water are common coolants used in various systems but water has better thermal conductivity and also better heat carrying capacity than air [19], and, consequently, a higher heat transfer rate. It is known that water can reduce the surface temperature of a PV module by approx. $22^{\circ} \mathrm{C}$ and, at the same time, the light reflection from the panel; on the other hand, the temperature of the module decreases by approx. $12^{\circ} \mathrm{C}$ when a heat sink with air cooling is used. The electrical efficiency of a PV panel does not always increase with an increasing air mass flow rate, but the water spray cooling enhances the performance of such systems considerably even at low water flow rates.

\subsection{Description of the proposed system configuration}

In order to investigate the coolant temperature behaviour, a PV panel integrated with various channel configurations is designed and simulated using commercial CFD software (Ansys-Fluent). In all the designs, water is used as the coolant due to its homogeneous thermophysical properties.

Six models are considered in this study (see Fig. 1). In the first model (Model A), water flows over the panel surface in a channel with a height of $2 \mathrm{~mm}$. In the second one (Model B), water flows over the panel surface in a channel with a height of $3 \mathrm{~mm}$. In the third model (Model C), cooling is done at the back side of the module, where a channel with $2 \mathrm{~mm}$ in height allows water to flow below the panel where it absorbs the heat. In the fourth design (Model D), water flows in a $3 \mathrm{~mm}$ high channel connected to the back side of the panel. The remaining two designs are different from the first four designs because fins are used inside the channel connected to the back side of the module. The height of the channels with fins was 3 $\mathrm{mm}$ in Model $\mathrm{E}$ and $4 \mathrm{~mm}$ in Model F. Fins are generally employed to increase the heat transfer from surfaces. The increased heat inside the panel is transferred to the water through these fins. Properties of the coolant and the fins used in the simulations are listed in Table 1. The fins are assumed to be made of aluminium because of high thermal conductivity coefficient of this metal.

Table 1 Finned channel and coolant properties

\begin{tabular}{ll}
\hline Material properties & Value \\
\hline Coolant & Water \\
Inlet temperature & $20^{\circ} \mathrm{C}$ \\
Conductivity & $0.6 \mathrm{~W} /(\mathrm{m} \cdot \mathrm{K})$ \\
Density & $998.2 \mathrm{~kg} / \mathrm{m}^{3}$ \\
Viscosity & $0.001003 \mathrm{~kg} /(\mathrm{m} \cdot \mathrm{s})$ \\
Fins & \\
Material & Aluminium \\
Conductivity & $202 \mathrm{~W} /(\mathrm{m} \cdot \mathrm{K})$ \\
Number & 6 \\
Thickness & $40 \mathrm{~mm}$ \\
Distance between fins & $60 \mathrm{~mm}$ \\
Water channel height & \\
Models (A,B,C,D) & $2 \mathrm{~mm}(\mathrm{~A}, \mathrm{~B}), 3 \mathrm{~mm}(\mathrm{C}, \mathrm{D})$ \\
Models (E and F) & $3 \mathrm{~mm}(\mathrm{E}), 4 \mathrm{~mm}(\mathrm{~F})$ \\
\hline
\end{tabular}



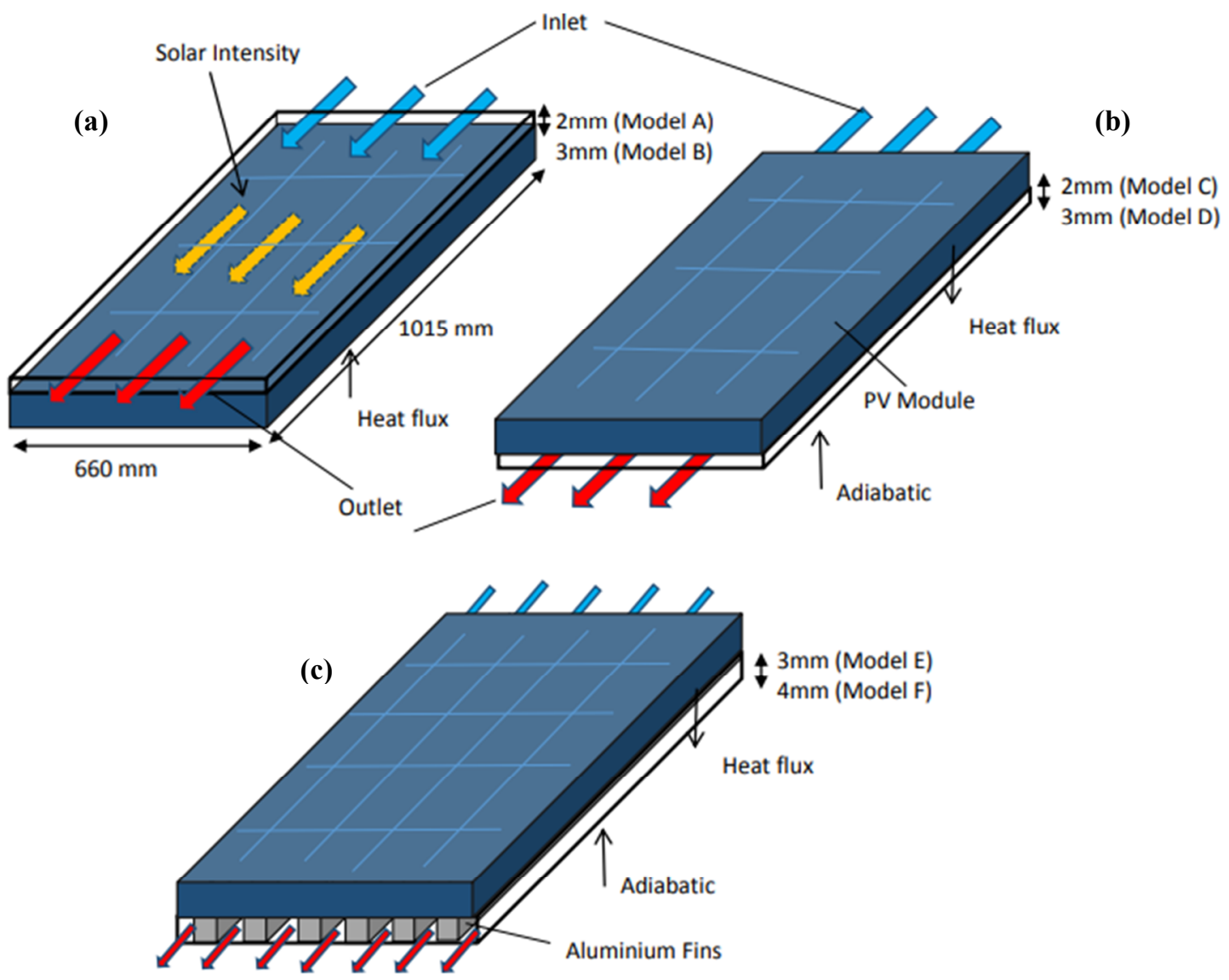

Fig. 1 Schematic picture of a photovoltaic panel with various cooling designs: a) Cooling channel on top of the panel, b) Cooling channel attached below the panel, c) Cooling channel with fins

\subsection{Numerical method}

In all simulations, the laminar flow regime is considered along the length of the panel. The water film thickness is assumed to be constant along the cooling channels. The temperature distribution over and below the panel is delineated by solving equations (1) to (3), which are equations for the conservation of mass, momentum, and energy in an incompressible fluid.

$$
\begin{aligned}
& \frac{\partial u_{j}}{\partial x_{j}}=0 \\
& \rho u_{j} \frac{\partial u_{i}}{\partial x_{j}}+\frac{\partial p}{\partial x_{i}}=\mu \nabla u_{i} \\
& \rho c u_{j} \frac{\partial T}{\partial x_{j}}=\frac{\partial}{\partial x_{j}}\left(k \frac{\partial T}{\partial x_{j}}\right)
\end{aligned}
$$

Here, $u$ and $x$ represent the velocity and direction vectors, respectively, $\rho$ is the density $\left(\mathrm{kg} / \mathrm{m}^{3}\right), p$ is the pressure $\mathrm{kg} /\left(\mathrm{m} \cdot \mathrm{s}^{2}\right), \mu$ is the fluid viscosity $(\mathrm{Pa} \cdot \mathrm{s}), T$ is the temperature $(\mathrm{K}), k$ is the thermal conductivity $\left(\mathrm{W} \cdot \mathrm{m}^{-1} \cdot \mathrm{K}^{-1}\right)$, and $\nabla$ is the Laplacian operator. In order to solve the equations, the following assumptions are made: constant flow velocity at the inlet, constant pressure at the outlet, and no-slip boundary condition on all walls.

The SIMPLE algorithm (Semi-Implicit Method for Pressure Linked Equations) is a well-known method used to obtain numerical solutions of the incompressible Navier-Stokes equations [20]. In this study, the SIMPLE algorithm is applied for coupling the continuity 
equations with the momentum equations. The solution was limited when residuals of $\mathrm{x}$ velocity, y-velocity, z-velocity, and energy equations were reduced below $10^{-6}$. A hexahedron mesh is selected for meshing. Different mesh elements are applied for the numerical solution of various models (Fig. 2). For the numerical solution of A, B, C, and D models, 200,000 mesh elements are used and for that of $\mathrm{E}$ and $\mathrm{F}$ models, 260,000 mesh elements. The empirical data obtained from experimental work carried out by Saygin et al. [21] was used to verify the designed model in ANSYS. The same PV module is used in the simulation and the experimental work. The PV module characteristics are shown in Table 2. As good agreement between the numerical and experimental results was achieved, the new cooling systems were designed and simulated.

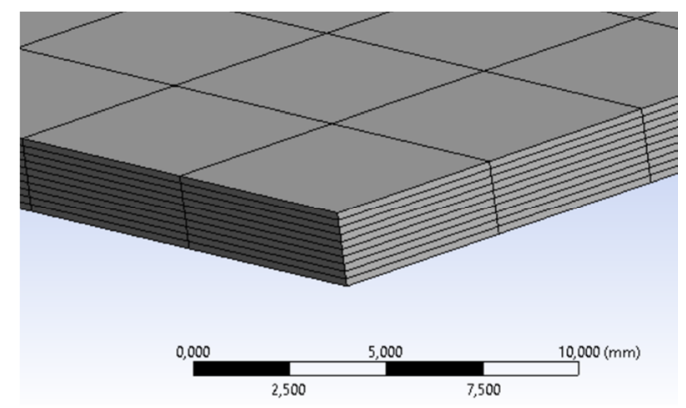

Fig. 2 Grid structure for coolant

Table 2 Specifications of the photovoltaic panel (PV)

\begin{tabular}{ll}
\hline Cell type & Polycrystalline \\
\hline Dimensions & $101.5 \mathrm{~cm} \times 66.6 \mathrm{~cm} \times 3.5 \mathrm{~cm}$ \\
Module maximum power $\left(P_{m}\right)$ & $80 \mathrm{~W}$ \\
Short circuit current $\left(I_{s c}\right)$ & $3.62 \mathrm{~A}$ \\
Open circuit voltage $\left(V_{o c}\right)$ & $29.40 \mathrm{~V}$ \\
Voltage at maximum power point $\left(V_{m}\right)$ & $23.88 \mathrm{~V}$ \\
Current at the maximum power point & $3.35 \mathrm{~A}$ \\
Standard packaging (modules per pallet) & 48 Pcs \\
Front cover & Tempered glass \\
Weight & $7.9 \mathrm{~kg}$ \\
\hline
\end{tabular}

\section{Results and Discussion}

In order to investigate the influence of different channel configurations on the coolant temperature and the heat flux, six models are designed and simulated with the ANSYS program. The simulation results are shown in the figures below. Variations in the water outlet temperature and the heat flux from the panel at different Reynolds numbers (Re) for Models $\mathrm{A}$ and $\mathrm{B}$ are shown in Fig. 3. The water inlet temperature was $20^{\circ} \mathrm{C}$ in all the simulations. In the figures below one can see that as the Reynolds number (Re) increases, the coolant outlet temperature decreases while the opposite happens with the heat flux. A higher Re value means a higher fluid velocity value, which leads to an increase in the heat flux; on the other hand, at higher flow velocities, water has less time to absorb the heat from the panel. As a result, the coolant outlet temperature falls at higher Re numbers. The maximum amount of heat flux $(22,603 \mathrm{~W})$ was observed at the highest Reynolds number (1800). The models are examined at various hours of the day (14:00 and 15:00). At 15:00, as the Reynolds number 
exceeded 1000, the temperature and the heat flux results became almost constant; therefore, the simulations were stopped at that step (Fig. 3 and 4). A comparison of the simulation results shows that the highest amount of heat transfer from the panel to the coolant $\left(\mathrm{Q}_{\text {out }}\right)$ occurs at 14:00 in Model A. In addition, the average water outlet temperature is found to be higher in Model A than in all other models. At the same Reynolds number (600), the water outlet temperature is found to be $39.03^{\circ} \mathrm{C}, 35.74^{\circ} \mathrm{C}, 38.34^{\circ} \mathrm{C}, 34.97^{\circ} \mathrm{C}, 34.89^{\circ} \mathrm{C}$, and $32.85^{\circ} \mathrm{C}$ in Models A, B, C, D, E, and F, respectively.

For Models C and D, the water channel was placed underneath the module. The results show that the average outlet temperature decreases with an increase in the channel height (Fig. 4). Similar results are observed in Models A and B in which the cooling channel was placed on top of the panel. In Model C, the water gets warmer and, therefore, the average outlet temperature rises. As shown in Fig. 5, the water pressure drop $(\Delta p)$ becomes bigger as the Reynolds number increases. This is observed in all the designs with upper or lower cooling channels (Models A, B, C, and D). But the enhancement is more obvious when the same models with different channel heights are considered. It is found that the models with smaller channel heights (Models A and C) show a bigger pressure drop. At the constant pumping power $\left(W_{P P}\right)$, the total pressure drop $(\Delta p)$ increases if the total volume flow rate $\left(Q_{v}\right)$ decreases; this is proved according to Equation (4) [22].

$$
W_{P P}=Q_{v} \cdot \Delta p
$$

where the units of $W_{P P}, Q_{v}$, and $p$ are watt, $\mathrm{m}^{3} / \mathrm{s}$, and pascal, respectively. For Models $\mathrm{E}$ and $\mathrm{F}$, variations in the average water outlet temperature and the heat flux from the panel at different Reynolds numbers are shown in Fig.6. It is found that the water outlet temperature decreases with an increase in the Reynolds number, while the heat flux exhibits the opposite behaviour. In Model E, the maximum amount of heat flux from the finned channel to the coolant of about $10,096 \mathrm{~W}$ is obtained at a Reynolds number of 1200. At 15:00, as the Reynolds number exceeded 500, the temperature and heat flux results became almost constant; therefore, the simulations were stopped at that step (Fig.6). The obtained results suggest that an increase in the fin (channel) height decreases the heat flux to the coolant and reduces the average outlet temperature. The outlet water temperatures obtained from Models $\mathrm{E}$ and $\mathrm{F}$ were $52^{\circ} \mathrm{C}$ and $49.8^{\circ} \mathrm{C}$ at a Reynolds number of 100 , respectively.

Changes in the water pressure drop in Models $\mathrm{E}$ and $\mathrm{F}$ are shown in Fig. 7. It is clear that an increasing height of the fin reduces the pressure drop through the channel. A comparison between Figures 5 and 7 shows that a finned channel causes a smaller pressure drop than a normal channel at the same flow rates. At the same Reynolds number (1000), the pressure drop values obtained from Model B (channel without fins) and Model E (finned channel) with the same channel heights $(3 \mathrm{~mm})$, are 232.6 $\mathrm{Pa}$ and 229.8 $\mathrm{Pa}$, respectively. The coolant temperature distributions for Models B and D for three values of Re number (100, 1000, and 1800) and a constant plate temperature of $55^{\circ} \mathrm{C}$ at 14:00 are shown in Fig. 8 and 10. At a constant plate temperature, as the Re number increases, the average coolant temperature decreases at the outlet, which means that the temperature difference between the inlet and the outlet water decreases as well. The results show that the water outlet temperature is higher in Model B than in Model D; therefore, the temperature difference between the inlet and the outlet water will be bigger in this model as well. The coolant pressure distribution for Model $\mathrm{B}$ is shown in Fig. 9. It is clear that the water pressure drop $(\Delta p)$ becomes bigger as the 
Reynolds number increases. It is also found that an increase in the channel height of $1 \mathrm{~mm}$ can considerably reduce the water pressure drop inside the channel.

Water temperature and pressure distributions for Model E, at Re numbers of 100, 600 and 1000 are presented in Fig. 11 and 12. As can be seen in Fig. 11, at different Re numbers, the temperature of the fin is almost uniform along its length but the temperature of the coolant varies. In Model E, with a fin of $3 \mathrm{~mm}$ in height, the coolant temperature rises to a maximum of about $32^{\circ} \mathrm{C}$ while in Model $\mathrm{F}$, with a fin of $4 \mathrm{~mm}$ in height, it rises to $29.8^{\circ} \mathrm{C}$ (Fig. 6). The way the coolant pressure is distributed inside the finned channels of Model E is shown in Fig. 12 together with the values of the coolant pressure. It is clear that the pressure drop is bigger at higher flow velocities, but still, it is smaller than the pressure drops in the models without fins.

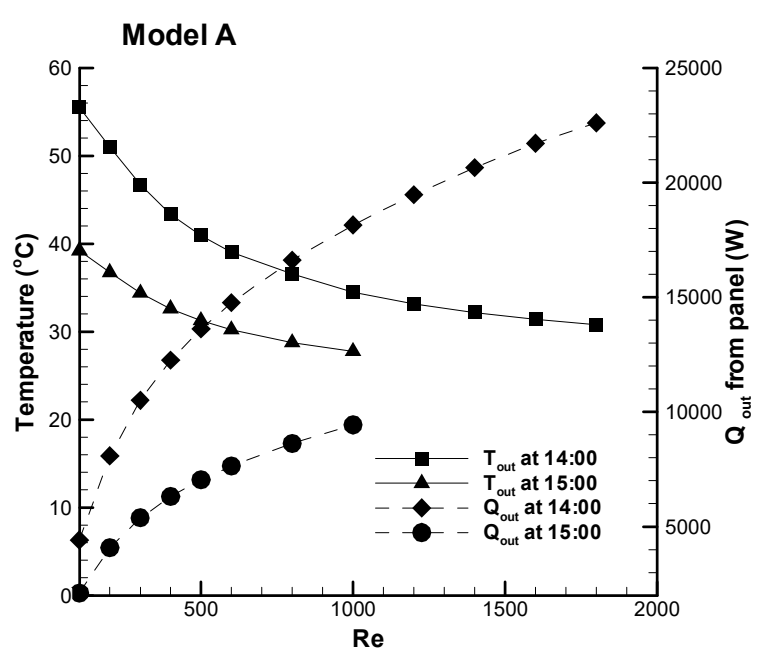

a)

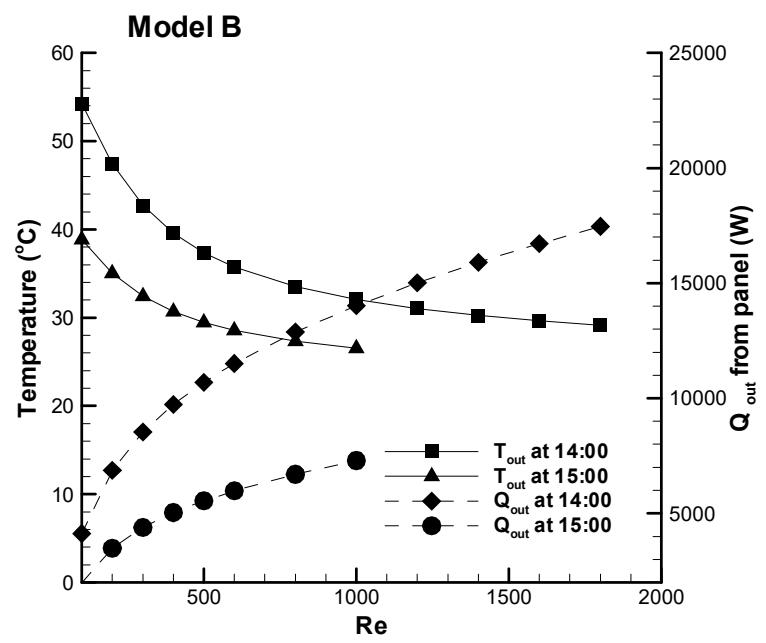

(b)

Fig. 3 Variations in the water outlet temperature and the heat flux from the panel at different Reynolds numbers for a) Model A and b) Model B.

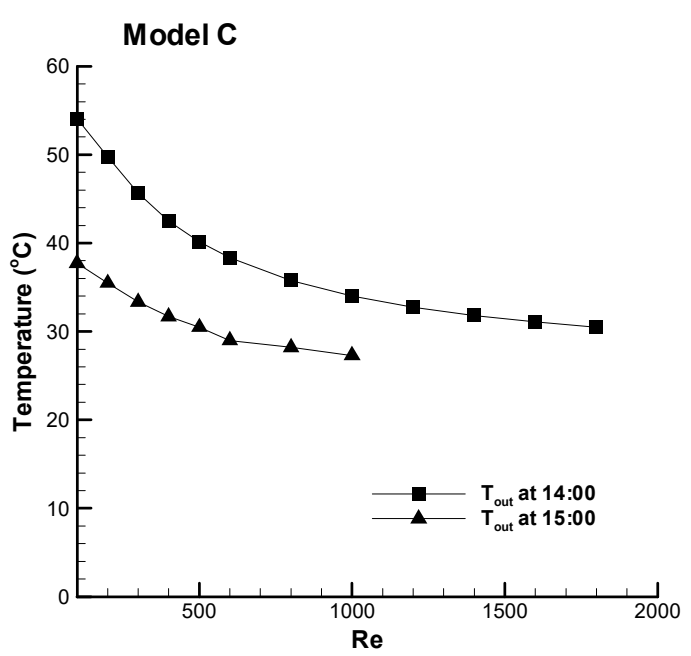

a)

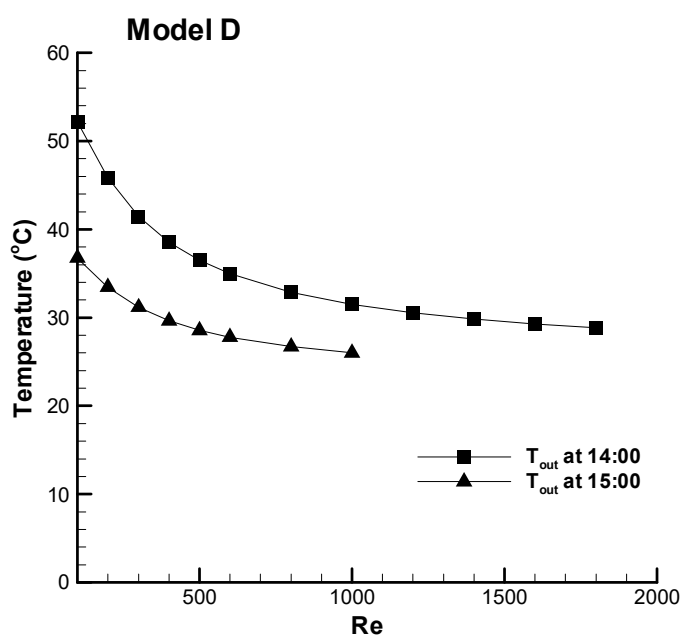

(b)

Fig. 4 Variations in the water outlet temperature at different Reynolds numbers for a) Model C and b) Model D. 

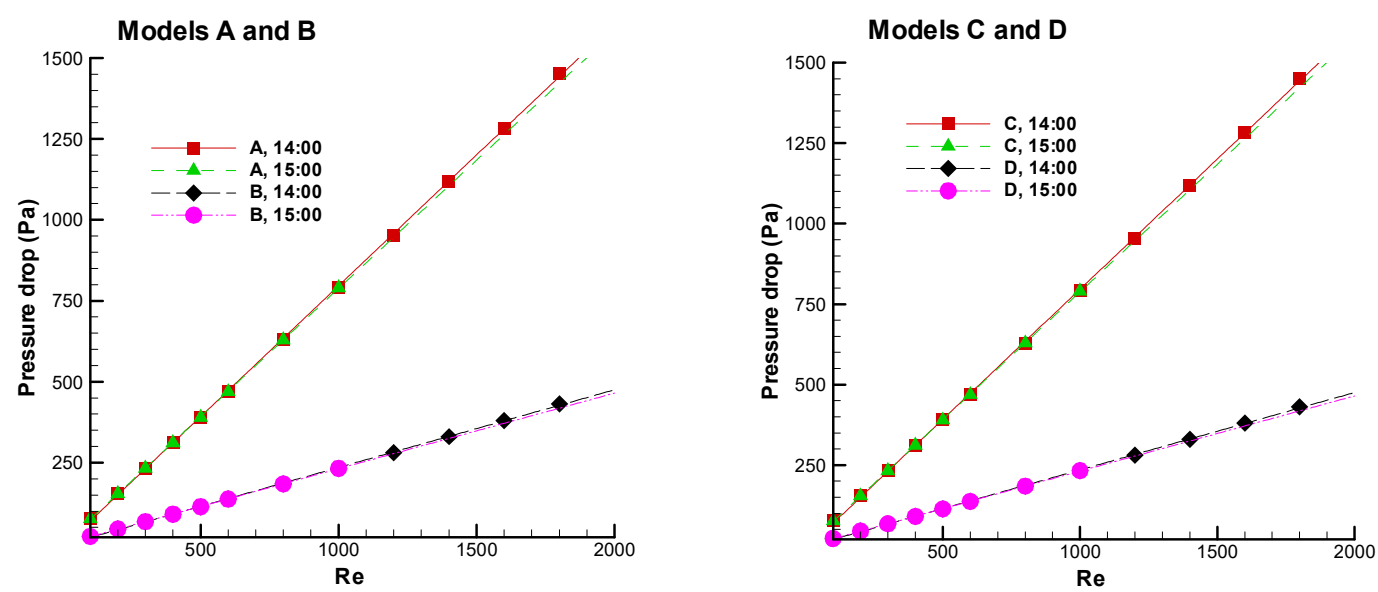

Fig. 5 Changes in the water pressure drop for Models A, B, C, and D at various Reynolds numbers.

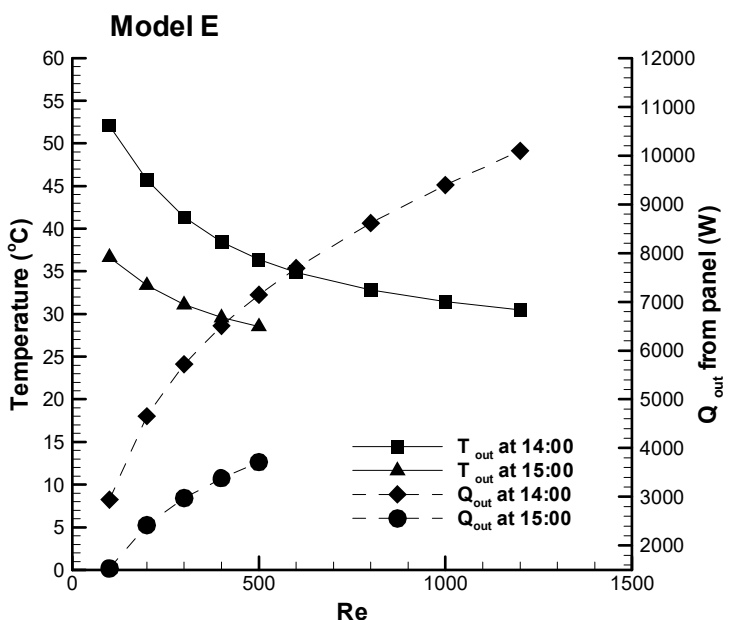

a)

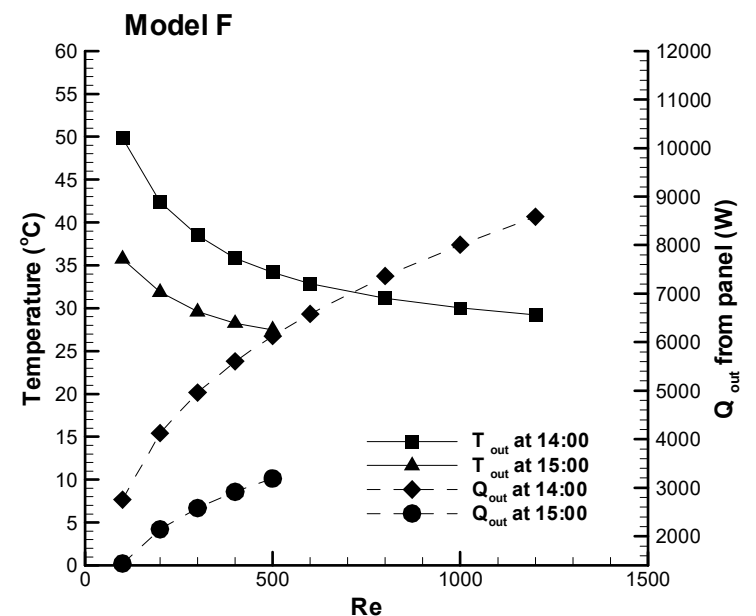

(b)

Fig. 6 Variations in the water outlet temperature and the heat flux from the panel at different Reynolds numbers for a) Model E and b) Model F.

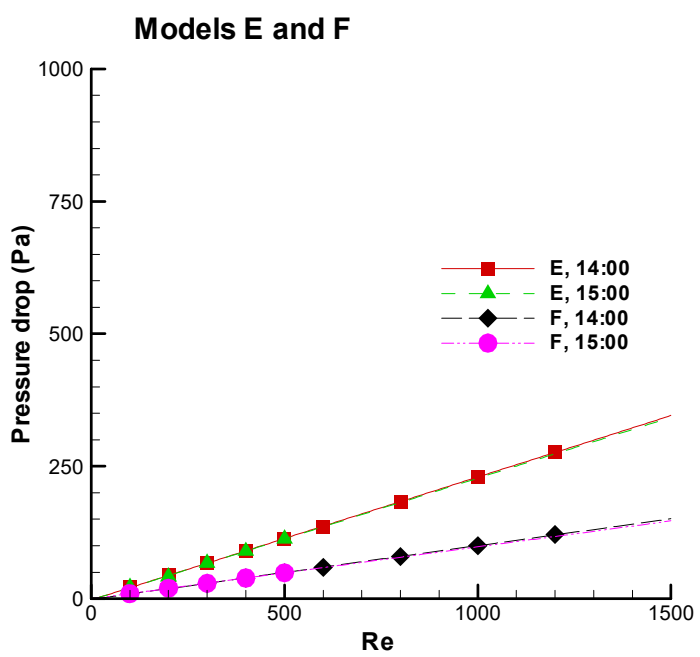

Fig. 7 Changes in the water pressure drop for Models E and F at various Reynolds numbers. 


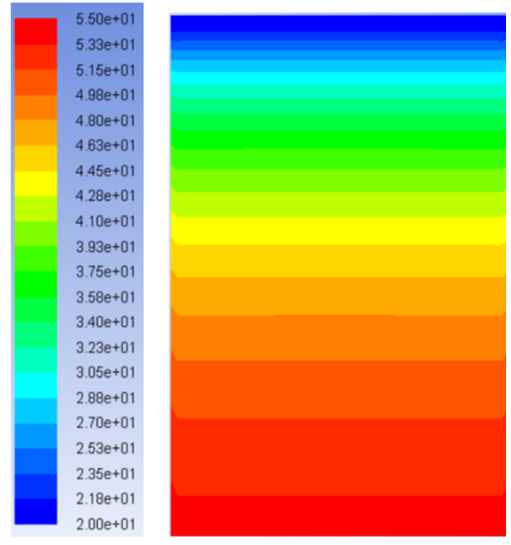

(a)

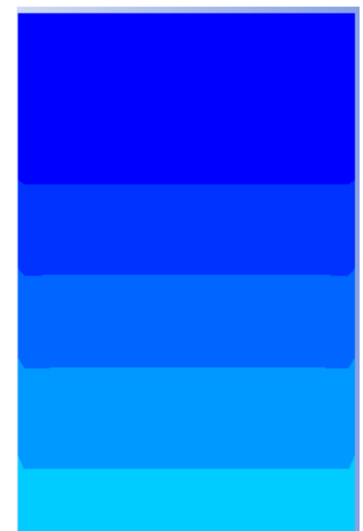

(b)

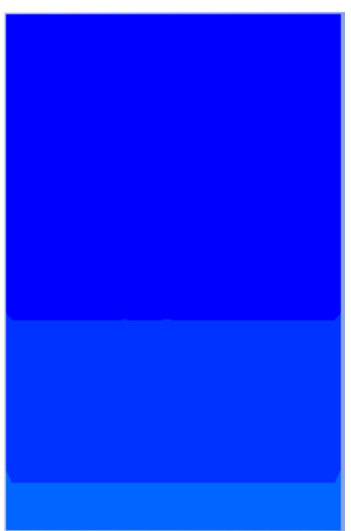

(c)

Fig. 8 Coolant temperature distribution for Model $B$ at a) $R e=100, b) R e=1000$, and c) $R e=1800$ at 14:00.

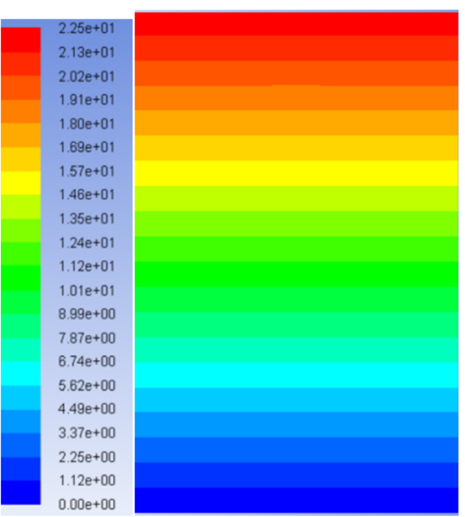

(a)

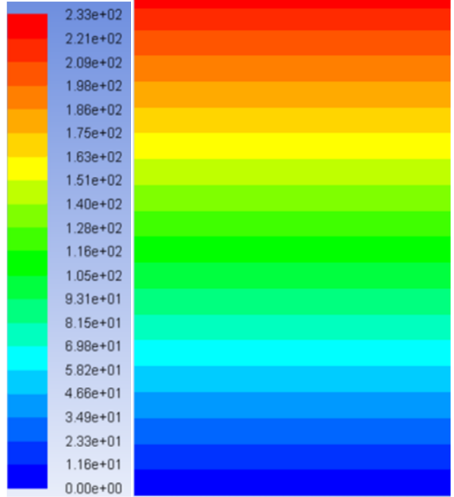

(b)

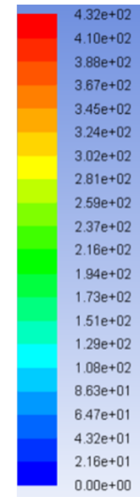

$0.00+00$

Fig. 9 Coolant pressure distribution for Model $B$ at a) $R e=100, b) \mathrm{Re}=1000$, and c) $\mathrm{Re}=1800$ at 14:00.

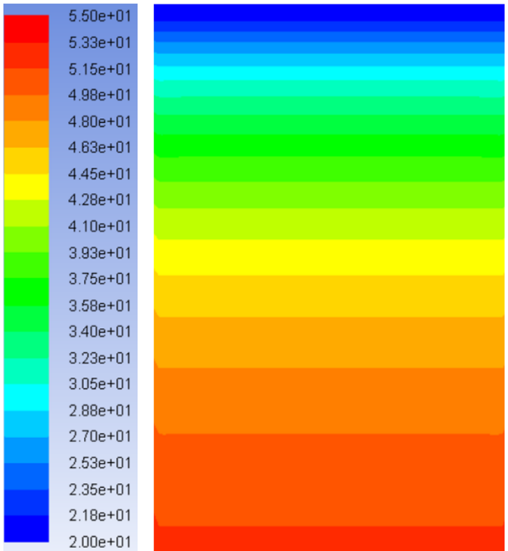

(a)

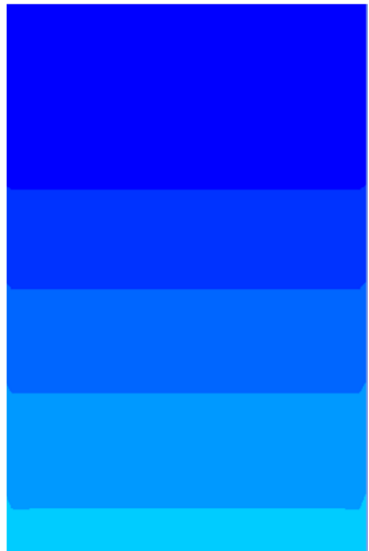

(b)

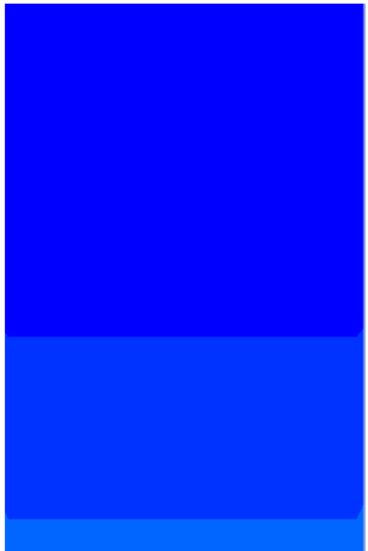

(c)

Fig. 10 Coolant temperature distribution for Model $D$ at a) $R e=100$, b) $R e=1000$, and c) $R e=1800$ at 14:00. 


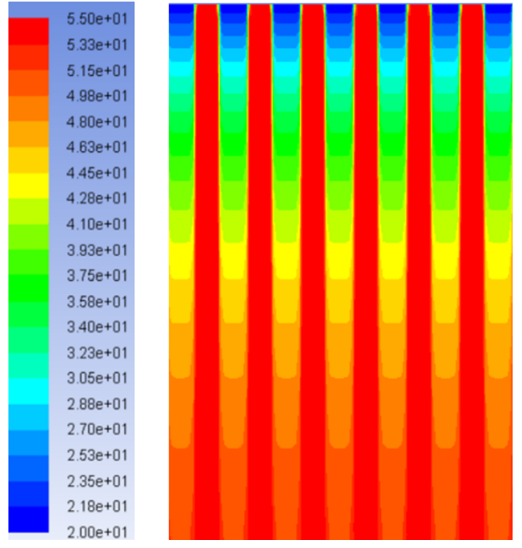

(a)

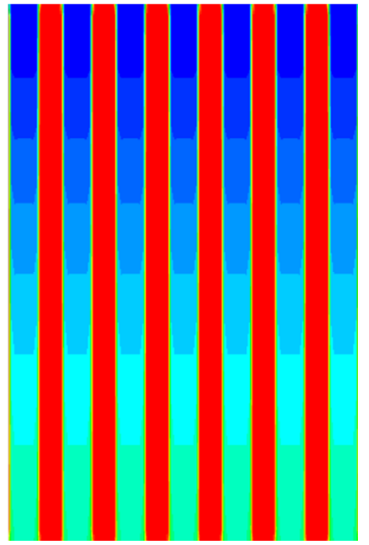

(b)

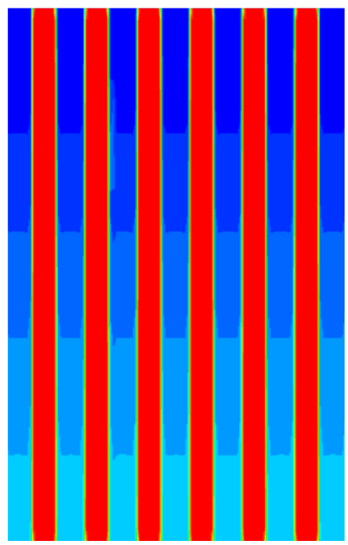

(c)

Fig. 11 Coolant temperature distribution for Model $\mathrm{E}$ at a) $\mathrm{Re}=100, \mathrm{~b}) \mathrm{Re}=600$, and c) $\mathrm{Re}=1000$ at 14:00.

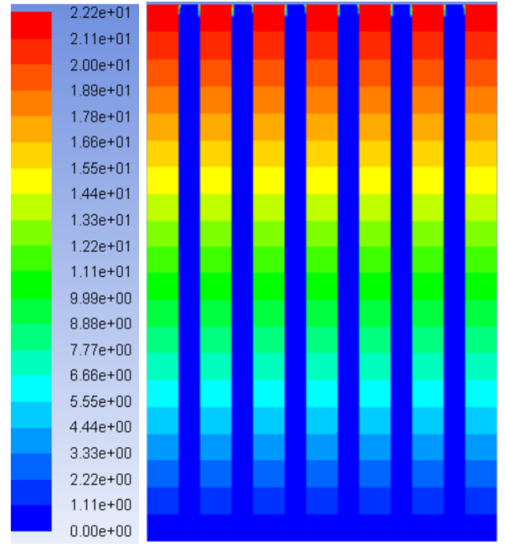

(a)

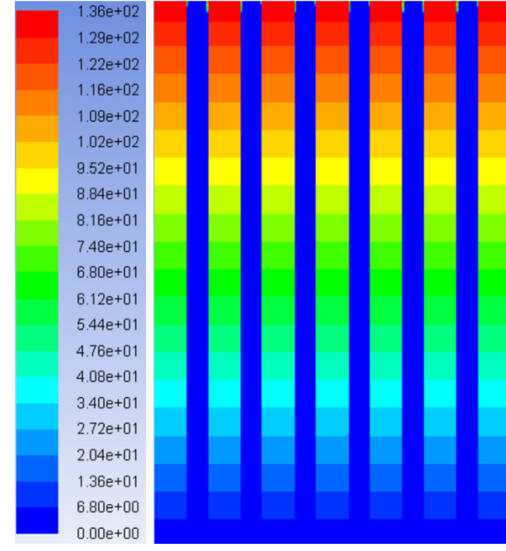

(b)

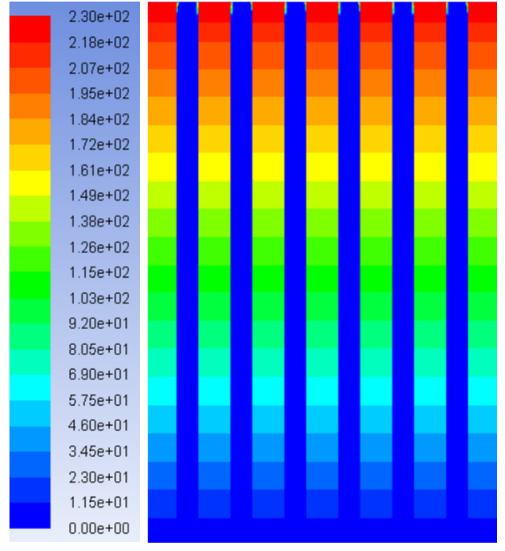

(c)

Fig. 12 Coolant pressure distribution for Model $\mathrm{E}$ at a) $\mathrm{Re}=100$, b) $\mathrm{Re}=600$, and c) $\mathrm{Re}=1000$ at 14:00.

\section{Conclusion}

The performance of a photovoltaic panel depends on many factors, one of which is its operating temperature. In many cooling techniques, water is sprayed on the panel to cool it, while in this study water is flowing above or below the module in a thin channel attached to it. This way the heated water does not evaporate and it is not wasted as it can be used in other domestic or industrial applications. In order to investigate the coolant temperature behaviour and the heat flux from the panel, a model is designed and simulated using commercial CFD software (ANSYS). Six different models are analysed in this study. In each simulation, changes in the heat flux, pressure drop, and coolant outlet temperature at different Reynolds numbers are calculated. Aluminium fins are also used in two models to examine their effect on the coolant temperature. Various channel heights are examined in the simulations. The obtained results show that as the Reynolds number increases, the coolant outlet temperature decreases while the heat flux exhibits the opposite behaviour in all models. Also, an increase in the channel height reduces the water pressure drop inside the channels. The highest amounts of heat extracted from the panel and the highest coolant outlet temperature are obtained in the case when the water flows over the module in a channel with a height of $3 \mathrm{~mm}$.

The focus of future work must be on harvesting heat from the panel surface in an effective, more stable and controlled manner. 


\section{REFERENCES}

[1] Wang, Y., Zhou, S. and Hou, H., Cost and $\mathrm{CO}_{2}$ reductions of solar photovoltaic power generation in China: perspectives for 2020. Renew Sustain Energy Rev 2014; 39:370-80. https://doi.org/10.1016/j.rser.2014.07.027

[2] Da Silva, R. M., and Fernandes, J. L. M., Hybrid photovoltaic/thermal (PV/T) solar systems simulation with Simulink/Matlab. Sol Energy 2010; 84:1985-96. https://doi.org/10.1016/j.solener.2010.10.004

[3] Kumar, K., Sharma, S. D. and Jain, L., Standalone Photovoltaic (PV) module outdoor testing facility for UAE Climate. Submitted to CSEM-UAE Innovation Centre LLC; 2007.

[4] Peng, Z., P., Herfatmanesh, M. R. and Liu, Y., Cooled solar PV panels for output energy efficiency optimization. Energy Conversion and Management 2017; 150:949-955. https://doi.org/10.1016/j.enconman.2017.07.007

[5] Chandrasekar, M. and Senthilkumar, T., Experimental demonstration of enhanced solar energy utilization in flat PV (Photovoltaic) modules cooled by heat spreaders in conjunction with cotton wick structures. Energy 2015; 90:1401-1410. https://doi.org/10.1016/j.energy.2015.06.074

[6] Nizetic, S., Coko, D., Yadav, A. and Grubišic Cabo, F., Water spray cooling technique applied on a photovoltaic panel: The performance response. Energy Conversion and Management 2016;108: 287-296. https://doi.org/10.1016/j.enconman.2015.10.079

[7] Saxena, A., Deshmukh, S., Nirali, S. and Wani, S., Laboratory-based Experimental Investigation of Photovoltaic (PV) Thermo-control with Water and its Proposed Real-time Implementation. Renewable Energy 2018; 115:128-138. https://doi.org/10.1016/j.renene.2017.08.029

[8] Schiro, F., Benato, A., Stoppato and A., Destro, N., Improving photovoltaics efficiency by water cooling: Modelling and experimental approach. Energy 2017;137: 798-810. https://doi.org/10.1016/j.energy.2017.04.164

[9] Jamil, R. P. and Yang, J., Comparison of heat sink and water type PV/T collector for polycrystalline photovoltaic panel cooling. Renewable Energy 2018;116: 479-491. https://doi.org/10.1016/j.renene.2017.09.090

[10] Darkwa, J. D. D., and Kokogiannakis, J. G., Thermal management systems for photovoltaics installations. Sol Energy 2013; 97:238-54. https://doi.org/10.1016/j.solener.2013.08.018

[11] Krauter S. Increased electrical yield via water flow over the front of photovoltaic panels. Sol Energy Mater Sol Cells 2004; 82:131. https://doi.org/10.1016/j.solmat.2004.01.011

[12] Grubišić-Čabo, F., Nižetić, S. and Tina Giuseppe Marco. Photovoltaic Panels: a review of the cooling techniques. Transactions of FAMENA XL, Special issue, 1, 2016.

[13] Baloch, A. A. B., Bahaidarah, H. M. S., Gandhidasan, P. and Al-Suleyman F. A. Experimental and numerical performance analysis of a converging channel heat exchanger for PV cooling. Energy Convers. Manage. 2015;103: 14-27. https://doi.org/10.1016/j.enconman.2015.06.018

[14] Rodgers, P. and Eveloy, V. An integrated thermal management solution for flat type solar photovoltaic modules. $14^{\text {th }}$ International Conference on Thermal, Mechanical and Multi-Physics Simulation and Experiments in Microelectronics and Microsystems (EuroSimE), 2013. https://doi.org/10.1109/eurosime.2013.6529993

[15] Moharram, K. A., Abd-Elhady, M. S., Kandil, H. A. and El-Sherif, H., Enhancing the performance of photovoltaic panels by water cooling. Ain Shams Eng. J. 4, 2013;4: 869-877. https://doi.org/10.1016/j.asej.2013.03.005

[16] Odeh, S. and Behnia, M., Improving photovoltaic module efficiency using water cooling. Heat Transf. Eng. 2009;30: 499-505. https://doi.org/10.1080/01457630802529214

[17] Idoko, L., Anaya-Lara, O. and McDonald, A., Enhancing PV modules efficiency and power output using multi-concept cooling technique. Energy Reports 2018; 4: 357-369. https://doi.org/10.1016/j.egyr.2018.05.004

[18] Sajjad, U., Amer, M., Ali, H.M., Dahiya, A., and Abbas, N, Cost effective cooling of photovoltaic modules to improve efficiency. Case studies in thermal engineering 2019; 14: 100420. https://doi.org/10.1016/j.csite.2019.100420

[19] Hugh, Y.D. and Weston Sears, F. University Physics, 7th Ed., Addison Wesley, 1992.

[20] Bathe, K.J. Computational fluid and solid mechanics. Vol. 2. Elsevier, 2001. 
[21] Saygin, H., Nowzari, R., Mirzaei, N. and Aldabbagh, L. B. Y., Performance evaluation of a modified PV/T solar collector: A case study in $t$ design and analysis of experiment. Sol Energy 2017; 141:210-221. https://doi.org/10.1016/j.solener.2016.11.048

[22] Wang, H., Chen, Z. and Gao, J., Influence of geometric parameters on flow and heat transfer performance of micro-channel heat sinks. Appl Therm Eng 2016; 107: 870-879.

https://doi.org/10.1016/j.applthermaleng.2016.07.039

Submitted: $\quad$ 16.7.2018

Accepted: $\quad 03.4 .2019$
Raheleh Nowzari

Mechanical Engineering Department, Istanbul Aydin University, Florya, Istanbul, Turkey 